\title{
2 Fitness costs associated with mounting a social immune response
}

4 Authors: S.C. Cotter $^{1}$, E. Topham ${ }^{1}$, A.J.P. Price ${ }^{1}$ \& R.M. Kilner ${ }^{1,2}$

5 Addresses: ${ }^{1}$ Department of Zoology, University of Cambridge, Downing Street, Cambridge,

6 CB2 3EJ, UK

$7 \quad{ }^{2}$ Center for Advanced Study, Drammensveien 78, NO-02171 Oslo, Norway

8 E-mail addresses: SC Cotter (sc570@ cam.ac.uk); E Topham

9 (eric.topham.fauchon@cantab.net), AJP Price (andrew.price@cantab.net), RM Kilner

10 (rmk1002@cam.ac.uk)

11 Corresponding author: Dr. Sheena Cotter, Department of Zoology, University of

12 Cambridge, Downing Street, Cambridge, CB2 3EJ, UK. Tel: +44 (0)1223 331861, Fax: +44

13 (0)1223 336676. Email: $\underline{\text { sc570@ cam.ac.uk }}$

14 Manuscript type: Letter

15 Running title: Fitness costs of social immunity

16 Keywords: social insect; phoresy; antimicrobial; sexual conflict; cooperation; mite;

17 ecological immunity

19 Abstract $=148$ words, Full text $=4818$, References $=53$, Figures $=3$, Tables $=1$ 


\section{$1 \quad$ Abstract}

2 Social immune systems comprise immune defences mounted by individuals for the benefit of

3 others (sensu Cotter \& Kilner 2010). Just as with other forms of immunity, mounting a social

4 immune response is expected to be costly but so far these fitness costs are unknown. We

5 measured the costs of social immunity in a sub-social burying beetle, a species in which two

6 or more adults defend a carrion breeding resource for their young by smearing the flesh with

7 antibacterial anal exudates. Our experiments on widowed females reveal that a bacterial

8 challenge to the breeding resource upregulates the antibacterial activity of a female's

9 exudates, and this subsequently reduces her lifetime reproductive success. We suggest that

10 the costliness of social immunity is a source of evolutionary conflict between breeding adults

11 on a carcass, and that the phoretic communities that the beetles transport between carrion

12 may assist the beetle by offsetting these costs.

13

14

15 


\section{Introduction}

2 Many organisms defend their fitness against attack from parasites and pathogens by mounting

3 an immune response. In addition to the well-known personal immune system, some immune

4 defences are deployed for the benefit of others, besides the challenged individual. For

5 example, some fish apply antimicrobial secretions onto their eggs (Knouft et al. 2003;

6 Giacomello et al. 2006) or to the nest surface (Little et al. 2008) for the benefit of their

7 developing young. Metapleural gland secretions in leafcutter ants are deployed against fungi

8 and bacteria that compete with their symbiotic fungus (Nascimento et al. 1996). Similarly,

9 termites and bark beetles coat the inside of their chambers respectively with antifungal faecal

10 pellets and oral secretions (Rosengaus et al. 1998; Cardoza et al. 2006). In the latter

11 examples, activation of the immune system brings benefits to neighbouring conspecifics and

12 even heterospecific members of the community (Fernandez-Marin et al. 2009), as well as the

13 immune-challenged individual. Whenever individuals mount an immune response for the

14 benefit of others as well as themselves, these are examples of social immunity. (Note that our

15 definition of the term "social immunity" is slightly broader than current one and readers may

16 wish to refer to Cotter \& Kilner (2010a) where we provide a full justification for our

17 terminology).

18 According to life history theory, maintaining any sort of immune response will come at a

19 cost (Sheldon \& Verhulst 1996). Identifying the nature and magnitude of these costs, and the

20 trade-offs they create, is central to understanding the evolution of immune systems (Sheldon

21 \& Verhulst 1996; Schulenburg et al. 2009). Consistent with this approach, there is

22 experimental evidence of costs associated with mounting a personal immune response

23 (Ilmonen et al. 2000; Moret \& Schmid-Hempel 2000; Siva-Jothy \& Thompson 2002;

24 Bonneaud et al. 2003; Jacot et al. 2004). Just as with the personal immune response, 
1 mounting a social immune response is also likely to be costly because it diverts resources

2 away from other functions (Lochmiller \& Deerenberg 2000). Indirect evidence that this is the

3 case comes from the observation that social immune responses are often upregulated only in

4 response to a specific challenge (e.g. Cotter \& Kilner 2010b; Fernandez-Marin et al. 2009).

5 Furthermore, where aspects of social immunity are constitutively expressed (examples in

6 Cremer et al. 2007; Fernandez-Marin et al. 2009), they are most typically shown by the non-

7 reproductive members of complex insect societies (Cremer et al. 2007). However, whether

8 there are any fitness costs directly associated with mounting a social immune response

9 remains unclear, partly because these immune responses are typically studied in social insects

10 where sterile workers are responsible for social immunity (Cremer et al. 2007). Nevertheless

11 identifying any fitness costs associated with responding to a social immune challenge is

12 important, not only for understanding related life history trade-offs, but also because it

13 potentially classifies social immunity as a form of cooperation (Hamilton 1964), with the

14 challenged individual providing a benefit to another individual at some cost to itself.

15 Here we measure the fitness costs of mounting a social immune response in the sub-social

16 burying beetle Nicrophorus vespilloides Herbst. Burying beetles exhibit elaborate biparental

17 care, with duties including the preparation and maintenance of a carcass to sustain their

18 developing young. They also defend the carcass and larvae from predators and competitors,

19 and feed their developing young with partially digested flesh from the corpse (Pukowski

20 1933). Carcass preparation involves stripping a small vertebrate corpse of fur or feathers,

21 rolling it into a ball, burying it in an underground chamber and covering it in anal and oral

22 exudates (Eggert \& Müller 1997, Scott 1998). Although these exudates have long been

23 assumed to serve an antimicrobial function, direct evidence to show that this is the case has

24 only recently been obtained (Cotter \& Kilner 2010b). 
1 This recent work shows that the anal exudates that parents smear on the carcass have

2 features in common with the immune function of insect haemolymph because they exhibit

3 lysozyme-like and phenoloxidase activity, which appear to trade-off against each other

4 (Cotter \& Kilner 2010b), an effect that has been shown in the internal immune system in

5 many different insect species (Moret \& Schmid-Hempel 2001; Rantala \& Kortet 2003;

6 Freitak et al. 2007; Cotter et al. 2008a; Povey et al. 2009). Whilst exudate lysozyme-like

7 activity is upregulated and facultatively adjusted upon discovery of a carcass, PO activity is

8 downregulated, suggesting that PO does not function as a preservative on the carcass (Cotter

$9 \&$ Kilner 2010b). The anal exudates protect resources on the carcass from microbial

10 competitors whose presence can dramatically reduce larval fitness (Rozen et al. 2008). The

11 anal exudates are therefore part of a social immune defence (Cotter \& Kilner 2010a),

12 functioning in exactly the same way as the metapleural gland secretions of worker ants (see

13 section 3 in Table 1 of Cremer et al. (2007)) to promote 'nest' hygiene for the benefit of

14 larvae. In the burying beetle, additional beneficiaries of this collective immune defence

15 include the beetle's mate and any unrelated adults whose larvae are raised on the same

16 carcass (brood parasitism or joint breeding occur in more than half of natural breeding attempts (Müller et al. 2007)). For all these reasons, the burying beetle's anal exudates constitute part of a social immune system.

Both parents take part in carcass preparation, but antibacterial exudates are primarily

20 produced by the female in $N$. vespilloides, although the male can partially compensate if

21 females are removed (Cotter \& Kilner 2010b). Our previous work suggests that maintaining high levels of antibacterial activity in the anal exudates is likely to be costly. Antibacterial activity is not constitutively expressed but induced by the presence of a carcass. Once a carcass is discovered, lysozyme-like antibacterial levels increase rapidly over two days and 
1 remain until the larvae disperse from the carcass. In addition, if either parent is removed from

2 the carcass before breeding is completed the antibacterial levels in their anal exudates fall

3 rapidly (Cotter \& Kilner 2010b).

4 Burying beetles offer the ideal opportunity to quantify fitness costs associated with social

5 immune responses because, unlike in many social insect species, reproductive adults

6 contribute to social immunity. Here we reveal fitness costs directly associated with mounting

7 this social immune response, that are independent of any other lifetime reproductive costs

8 associated with parental care (Ward et al. 2009). Our experiments involve exposing females

9 to carcasses that have been bacterially challenged and then monitoring their subsequent

10 lifetime breeding success and survival.

12 Materials and Methods

\section{$13 \quad$ N. vespilloides colony}

14 The Nicrophorus vespilloides colony was established in May 2005 from wild-caught beetles

15 which had been trapped in Madingley Woods, Cambridge, UK. Wild beetles were collected 16 from Byron's Pool local nature reserve, Cambridge, UK each subsequent year during August

17 and added to the colony to maintain genetic diversity. Beetles were reared in a temperature

18 controlled room at $21^{\circ} \mathrm{C}$ with a $16: 8$ light:dark cycle. Unrelated pairs were placed in a plastic

19 container $(17 \times 12 \times 6 \mathrm{~cm})$, one-third filled with moist, non-sterile soil, and provided with a

20 newly defrosted mouse carcass $(10.82 \pm 0.2 \mathrm{~g})$. The breeding box was kept in the dark to

21 simulate underground conditions. Offspring disperse from the carcass approximately 8 days

22 after the parents have been paired. At this point larvae were removed from the soil and placed

23 individually in plastic boxes $(12 \times 8 \times 2 \mathrm{~cm})$ filled with moist soil. Upon reaching adulthood, 
1 beetles were fed twice a week on small pieces of minced beef until required for experiments

2 or breeding. Between 50 and 150 pairs successfully produced offspring each generation.

3 Animals had been reared under standard laboratory conditions for 20 generations at the start

4 of the experiment. For all experiments, beetles were approximately 2 weeks old at first

5 mating (Mean \pm SE age in days $=15.13 \pm 0.37$ ).

6

\section{$7 \quad$ Experiment 1: Forced upregulation of exudate antibacterial activity}

8 Before attempting to uncover any fitness costs associated with induced antibacterial activity

9 in the anal exudates, we first had to develop a technique to force females to upregulate their

10 antibacterial activity to a higher level than would normally be required on a fresh carcass. To

11 do this we decided to simulate experimentally the natural situation of a female finding a

12 carcass that was in an advanced state of decay. A potential problem here is that a decaying

13 carcass offers a poorer quality resource for larval growth (Rozen et al. 2008), and so any

14 subsequent effects on lifetime reproductive success could be due to the quality of the carcass

15 rather than altered behaviour by the parents. To overcome this difficulty, we dipped fresh

16 carcasses in an overnight culture of Micrococcus lysodeikticus in nutrient broth that was

17 either live (live bacteria) or that had been autoclaved (dead bacteria). M. lysodeikticus is a

18 soil bacterium that does not degrade the quality of the carcass but its presence on the carcass

19 should indicate to the female that the corpse is bacterially compromised. Although the

20 bacteria do not compromise survival (see Results) it is possible that they have sublethal

21 effects on reproduction. Therefore we used the heat-killed bacterial treatment as a way of

22 upregulating antibacterial exudates whilst controlling for any potential negative effects on the

23 beetle of an actively replicating bacterium. As a positive control, carcasses were dipped in 
1 sterile nutrient broth whilst the negative control carcasses were left unmanipulated. Virgin

2 females were then each placed on a carcass in a breeding box with a virgin male and left to

3 prepare the carcass for breeding. After 2 days, exudates were sampled from all females and

4 stored at $-20^{\circ} \mathrm{C}$ until further analyses were carried out.

5 Upon handling, the majority of our laboratory beetles produce a brown exudate from their

6 abdomen, which can be easily collected using a glass capillary tube and blown into an

7 eppendorf tube for storage. Lytic activity in the exudates against the bacterium Micrococcus

8 lysodeikticus was determined using a lytic zone assay. Agar plates were prepared containing

$910 \mathrm{ml}$ of $1 \%$ agar with $5 \mathrm{mg}$ per $\mathrm{ml}$ freeze-dried M. lysodeikticus. For each plate, 20 holes

10 with a diameter of $2 \mathrm{~mm}$ were punched in the agar and $1 \mu \mathrm{l}$ of exudate was placed in each

11 well, two replicates per sample. The plates were incubated at $25^{\circ} \mathrm{C}$ for $24 \mathrm{~h}$ then

12 photographed using a digital camera. The diameter of the clear zones was calculated using

13 Image $J$ software. Standard curves were obtained using a serial dilution of hen egg white

14 lysozyme and the concentration of lysozyme in $\mathrm{mg} / \mathrm{ml}$ was then calculated.

15 Additionally, phenoloxidase activity was measured in the exudates using a modified version 16 of the method described in Cotter et al (2008b). In brief, $1 \mu \mathrm{l}$ of exudate was added to $100 \mu \mathrm{l}$ 17 of ice-cold phosphate buffered saline (PBS, pH 7.4) in a plastic Eppendorf tube and vortexed.

18 This assay involved adding $100 \mu \mathrm{l}$ of $4 \mathrm{mM}$ dopamine to $45 \mu \mathrm{l}$ of the buffered exudate and

19 incubating duplicate samples of the mixture on a temperature-controlled Biotek ELX808

20 microplate reader (BioTek Instruments Inc., Winooski, VT, US) at $490 \mathrm{~nm}$ at $30^{\circ} \mathrm{C}$. PO

21 activity was expressed as the change in absorbance over the first 15 minutes, which is during

22 the linear phase of the reaction. 


\section{Experiment 2: Survival costs of antibacterial upregulation after a single breeding bout}

2 Having developed a technique for upregulating antibacterial activity in the anal exudates, we

3 next investigated whether antibacterial upregulation was associated with any subsequent

4 survival costs, in the absence of further reproductive attempts. Virgin females were assigned

5 to one of three treatment groups: control, broth-dipped or bacteria-dipped carcasses as

6 described above. For each treatment, 42 pairs were established. Of these, there were 26

7 successful breeding pairs in the control treatment, 27 successful pairs in the broth-dipped

8 carcass treatment and 23 successful pairs for the bacteria-dipped carcass treatment. Each

9 female was paired with an unrelated virgin male, and both were placed on a carcass in their

10 own breeding box. All males were removed after $24 \mathrm{~h}$. Females were then left to prepare the

11 carcass and raise offspring. At dispersal, each larva was weighed and the number of

12 dispersing larvae for each female noted. Females were then placed back into individual

13 containers and fed twice weekly until death.

14 Females may be able to recoup the costs of antibacterial upregulation if food is provided $a d$

15 libitium throughout the reminder of their lives. If this is the case then any survival costs

16 associated with mounting a social immune response may only be apparent during starvation.

17 To test this possibility, a further 60 pairs of virgin beetles were established, 30 with broth-

18 dipped and 30 with bacteria-dipped mice. Of these, 21 pairs in the bacteria treatment and 22

19 pairs in the broth treatment bred successfully. Females were allowed to breed in these two

20 treatments exactly as described above but after breeding, females were kept without food

21 until they died. 


\section{Experiment 3: Survival and fecundity costs of antibacterial upregulation with multiple}

\section{2 breeding bouts}

3 This experiment was designed to test first, whether there were fecundity costs associated with

4 antibacterial upregulation and second, whether survival costs of upregulation were apparent if

5 females were given the opportunity to reproduce throughout their life. This experiment was

6 carried out in two replicates. In the first replicate virgin females were assigned to one of two

7 treatments: breeding with either a sterile broth-dipped carcass or a carcass that had been

8 dipped in live bacteria for their first two broods. In the second replicate a further dead

9 bacteria treatment was included to rule out the possibility that any costs were due to

10 pathogenic effects of the bacteria. For their subsequent breeding attempts, females in each

11 treatment were allowed to breed on untreated carcasses, with three days to rest between

12 breeding bouts, and they were induced to breed repeatedly until they died. For each breeding

13 attempt, females were paired with a new young, virgin male and larvae were collected at

14 dispersal, weighed and counted. 105 pairs were set up but 7 of the pairs failed to reproduce in

15 any brood ( 2 sterile, 3 dead and 2 live bacteria) and so were removed from the analyses,

16 leaving 98 pairs in total.

18 Statistical analyses

19 The longevity data were analysed using age-specific, parametric survival models in S-Plus 7

20 (Tibco, Basingstoke, UK) using a Weibull distribution, which assumes that the risk of death

21 increases with age. All other data were analysed using linear mixed effects REML models in

22 Genstat 10 (VSN International, Hemel Hempstead, UK) with the family from which the focal

23 beetle originated included as a random effect. In the analysis of repeated breeding we first

24 checked that there were no significant differences between the replicates for the live bacteria 
1 and broth-dipped treatments $\left(\mathrm{F}_{1,408}<2.28, \mathrm{P}>0.13\right)$; data for the two replicates was then

2 pooled for the final analysis and the identity of the pair was also included as a random effect.

3 In all models, the weight of the carcass that beetles bred on was included as a covariate,

4 because carcass weight influences the size and number of offspring reared (see experiment 2)

5 and because carcass size might be a confounding influence on the up-regulation of

6 antibacterial activity in the anal exudates. Estimation of the goodness of fit of a mixed effects

7 REML model is not straightforward as there is no equivalent statistic to the $\mathrm{r}^{2}$ available.

8 Therefore, to estimate the goodness of fit of our models, fitted values from each of the

9 models were regressed against the original data and an $\mathrm{r}^{2}$ of this regression is reported. Means

$10 \pm$ standard errors are reported throughout.

12 Results

\section{Experiment 1: Forced upregulation of exudate antibacterial activity}

14 Presenting female beetles with bacterially challenged carcasses successfully forced them to

15 upregulate their lysozyme activity to higher levels than would typically be seen when breeding on a fresh carcass. There was a significant effect of carcass treatment on lytic activity in the females' anal exudates $\left(\mathrm{F}_{3,131}=14.05, \mathrm{P}<0.001\right.$; Fig. 1). Dipping the carcass significantly upregulated lysozyme activity over undipped controls $\left(\mathrm{t}_{82}>3.9, \mathrm{P}<0.001\right)$.

19 Amongst the dipped carcasses, females breeding on a bacteria-dipped carcass had significantly greater levels of lytic activity in their anal exudates than females breeding on a sterile broth-dipped carcass $\left(\mathrm{t}_{125}>2.546, \mathrm{P}<0.012\right.$; Fig. 1$)$. However, exudates activity did not differ significantly between females breeding on live or dead bacteria-dipped carcasses 
$1 \quad\left(t_{112}=1.004, P=0.32\right.$; Fig. 1$)$ and PO activity did not differ between any of the treatment

$2 \operatorname{groups}\left(\mathrm{F}_{2,79}=1.25, \mathrm{P}=0.29\right)$.

4 Experiment 2: Survival costs of antibacterial upregulation after a single breeding bout

5 When females bred just once in their lives, we could detect no survival costs associated with

6 antibacterial upregulation. Females that bred on a bacteria-dipped carcass survived at a

7 similar rate as those that had bred on either sterile broth-dipped or control carcasses (Minimal

8 model containing treatment only: $\left.\chi_{2}^{2}=3.32, \mathrm{P}=0.19\right)$. Survival rates were also unrelated to

9 the weight of the mouse carcass used for breeding $\left(Z_{83}=-1.029, P=0.30\right)$, female age at

10 mating $\left(\mathrm{Z}_{83}=0.187, \mathrm{P}=0.85\right)$, the number of offspring produced $\left(\mathrm{Z}_{83}=-1.033, \mathrm{P}=0.30\right)$ or

11 the brood's total mass $\left(Z_{83}=-0.676, P=0.50\right)$. One possible explanation for these non-

12 significant results is that females recoup any survival costs associated with antibacterial

13 upregulation by feeding after breeding. However, when we analysed the survival of females

14 that were starved after breeding, we again found no significant effect of carcass treatment on

15 female survival (Minimal adequate model containing treatment only: $\chi^{2}{ }_{2}=0.27, P=0.99$ ).

16 We wondered whether females might have shunted any costs associated with upregulated

17 antibacterial activity onto the current brood, by skimping on post-hatching care. However, we

18 could detect no effect of carcass treatment on either the number of larvae produced $\left(\mathrm{F}_{2,129}=\right.$

$191.89, \mathrm{P}=0.156)$, the total brood mass $\left(\mathrm{F}_{2,120}=0.53, \mathrm{P}=0.587\right)$, or on the average larval mass

20 at dispersal $\left(\mathrm{F}_{2,120}=1.16, \mathrm{P}=0.316\right)$. Nevertheless, there were positive effects of carcass

21 weight on each of the offspring traits we measured (number of larvae: $F_{1,123}=4.07, P=$

22 0.046; total brood mass: $\mathrm{F}_{1,119}=32.18, \mathrm{P}<0.001$; average larval mass at dispersal: $\mathrm{F}_{1,74}=$ $2330.66, \mathrm{P}<0.001)$. 


\section{Experiment 3: Survival and fecundity costs of antibacterial upregulation with multiple}

\section{3 breeding bouts}

4 Forcing females to breed repeatedly throughout their lives uncovered a survival cost

5 associated with mounting a social immune response. Females that had bred on bacteria-

6 dipped carcasses in the first two breeding attempts subsequently died at a faster rate than

7 females breeding on control carcasses (live bacteria vs sterile broth: $\mathrm{Z}_{94}=3.89, \mathrm{P}<0.001$,

8 dead bacteria vs sterile broth: $\mathrm{Z}_{94}=4.92, \mathrm{P}<0.001$; Fig. 2). Females breeding on carcasses

9 dipped in dead bacteria also died more quickly than females breeding on carcasses dipped in

10 live bacteria $\left(\mathrm{Z}_{62}=4.55, \mathrm{P}<0.001 ;\right.$ Fig. 2$)$. In addition, females that bred on heavier

11 carcasses on average throughout their lives also died at a faster rate, independent of the

12 carcass bacterial treatment $\left(\mathrm{Z}_{94}=3.99, \mathrm{P}<0.001\right)$. Survival was influenced by the number of

13 offspring that females produced during the first two broods $\left(\mathrm{Z}_{94}=2.37, \mathrm{P}=0.017\right)$, but not by

14 the mass of offspring produced from these broods $\left(\mathrm{Z}_{94}=0.987, \mathrm{P}=0.32\right)$.

15 There was a marginally non-significant trend for females that had bred on live bacteria-

16 dipped carcasses to produce fewer successful broods during their lifetime (Mean $( \pm$ SE)

17 sterile broth $=4.90$ broods $( \pm 0.25)$, dead bacteria $=4.89$ broods $( \pm 0.38)$, live bacteria $=4.15$

18 broods $\left.( \pm 0.26) ; F_{2,96}=2.69, P=0.073\right)$. We looked in more detail at the success of each

19 breeding attempt by females in the three treatments. We considered the effects of brood and

20 treatment on the number, mean weight and total weight of larvae produced. In each case there

21 was a significant interaction between brood and treatment. After controlling for the effect of

22 carcass weight $\left(\mathrm{F}_{1,460}=96.67, \mathrm{P}<0.001\right)$, the number of larvae that survived to disperse

23 tended to decrease with each successive brood, but this decrease was significantly more 
1 marked in females that initially bred on both live and dead bacteria-dipped carcasses than

2 those in the control treatment (brood*treatment: $\mathrm{F}_{8,380}=3.13, \mathrm{P}=0.002$; Fig 3a). After

3 controlling for carcass weight $\left(\mathrm{F}_{1,456}=175.63, \mathrm{P}<0.001\right)$, mean brood mass declined rapidly

4 with each successive brood in the dead bacteria treatment, but mean weight only declined

5 marginally in the live bacteria treatment (brood*treatment: $\mathrm{F}_{8,377}=3.19, \mathrm{P}=0.002$; Fig $3 \mathrm{~b}$ ).

6 The combined effect of these two factors meant that total brood weight declined with each

7 brood, with the strongest decline being in the dead bacteria treatment and the weakest decline

8 in the sterile controls, with the live bacteria treatment showing an intermediate reduction in

9 total brood mass (brood*treatment: $\mathrm{F}_{8,380}=3.39, \mathrm{P}<0.001$; Fig. $3 \mathrm{c}$ ), even after controlling

10 for carcass weight $\left(\mathrm{F}_{1,456}=233.48, \mathrm{P}<0.001\right)$. In each case the $\mathrm{r}^{2}$ from the minimum

11 adequate model was higher than for the alternate models (Table 1).

12 There was no significant difference in any of the measures of reproductive investment in the

13 first two broods where females were exposed to treated carcasses (number of larvae: $\mathrm{F}_{2,96}=$ $140.25, \mathrm{P}=0.78$; mean larval mass: $\mathrm{F}_{2,96}=0.20, \mathrm{P}=0.82$; total larval mass: $\mathrm{F}_{2,96}=1.77, \mathrm{P}=$

15 0.18) and overall, females from either of the bacteria-dipped carcass treatments had

16 significantly lower lifetime reproductive success than control females, producing fewer

17 offspring during their lives (Mean $( \pm$ SE) sterile broth $=85.3$ larvae $( \pm 2.7)$, live bacteria $=$

1873.0 larvae $( \pm 3.84)$, dead bacteria $=70.2$ larvae $\left.( \pm 7.2) ; \mathrm{t}_{1,74}>2.63, \mathrm{P}<0.01\right)$, of lower

19 average mass $($ Mean $( \pm$ SE) sterile broth $=0.1310 \mathrm{~g}( \pm 0.0037)$, live bacteria $=0.1144 \mathrm{~g}( \pm$

20 0.0063), dead bacteria $\left.=0.1059 \mathrm{~g}( \pm 0.0082) ; \mathrm{t}_{1,74}>2.27, \mathrm{P}<0.026\right)$, resulting in a lower total

21 brood mass (Mean $( \pm \mathrm{SE})$ sterile broth $=11.74 \mathrm{~g}( \pm 0.35)$, live bacteria $=10.02 \mathrm{~g}( \pm 0.50)$,

22 dead bacteria $\left.=9.38 \mathrm{~g}( \pm 0.88) ; \mathrm{t}_{1,74}>2.82, \mathrm{P}<0.0062\right)$. There was no significant difference

23 between the two bacteria treatments in any measure of LRS $\left(\mathrm{t}_{1,74}<0.828, \mathrm{P}>0.41\right)$. 


\section{Discussion}

2 By forcing breeding female burying beetles to upregulate antibacterial activity in their anal

3 exudates, we uncovered substantial lifetime fitness costs associated with mounting this form

4 of social immune response (Fig. 3). Females induced to produce exudates with greater levels

5 of antibacterial activity reared, on average, 14 fewer offspring during their lives than control

6 females, representing a 16\% decrease in lifetime reproductive output. To our knowledge, this

7 the first evidence that mounting an immune response of any sort (i.e. social or personal) bears

8 associated costs that reduce lifetime reproductive success, independent of any costs imposed

9 by a parasite.

10 For females breeding on bacterially-challenged carcasses, their reduced lifetime

11 reproductive success was the result of an accelerated age-related decline in fecundity coupled

12 with lower rates of survival. Females exposed to live bacteria maintained a similar average

13 larval mass at dispersal across breeding attempts, but those exposed to dead bacteria showed

14 a rapid decline in larval brood mass. It is not clear why exposure to dead bacteria would

15 result in a stronger response than exposure to live bacteria, but one possibility is that

16 autoclaving the live culture could break up the cells, presenting many more "pieces" of

17 bacteria, which may give the impression of a larger bacterial dose.

In both bacteria treatment groups, the number of dispersing larvae produced declined rapidly with each successive brood, resulting in a lower total brood mass than in control

20 females. Therefore either these females laid fewer eggs per brood than control females, or

21 they cannibalized a larger proportion of their hatchlings than controls (Bartlett \& Ashworth

22 1988). We can be confident that the reduced survival rates shown by females that bred

23 initially on bacteria-dipped carcasses (Fig. 2) were not due to any pathogenic effects of the 
1 bacteria on the carcass because females exposed to these bacteria in a single breeding attempt

2 did not subsequently die at a faster rate than control females (Experiment 2). Additionally,

3 the survival rates of females exposed to dead bacteria were lower even than those of females

4 exposed to live bacteria, ruling out the possibility that the actively replicating bacterium was

5 compromising the health of females.

6 It might be argued that the costs we report here are not causally related to mounting

7 an immune response, but instead are correlated with other duties of parental care such as

8 skinning of the carcass, or larval provisioning. However, our experimental results allow us to

9 reject this alternative interpretation of the data. We can be confident that the effort devoted to

10 carcass skinning did not account for the differences between the treatments because we

11 statistically controlled for the weight of the carcass in each of the models. Although there was

12 an effect of carcass size on subsequent female survival, there was an additional independent

13 effect of carcass bacterial treatment on female lifespan. We have previously shown that larval

14 provisioning carries lifetime reproductive costs in these beetles (Ward et al. 2009), but our

15 experiments show that lytic activity in the anal exudates is up-regulated independently of

16 larval provisioning. Beetles with higher levels of lytic activity in their anal exudates did not

17 provide their offspring with more food, because brood mass, a key indicator of parental

18 provisioning (e.g. Rozen et al. 2008), did not differ between the treatments on the

19 manipulated carcasses (Experiments 2 and 3). Consequently, the lifetime reproductive costs

20 exposed in Experiment 3 must be attributable to the up-regulation of lytic activity in the anal

21 exudates. Therefore, our experiments here, and elsewhere (Ward et al. 2009), show for the

22 first time that different components of parental care, namely antibacterial carcass defence and

23 larval provisioning, each carry independent lifetime reproductive fitness costs. 
The substantial fitness costs associated with mounting a social immune response

2 explain why beetles upregulate the lytic activity in their exudates only when it is required,

3 namely during carcass preparation and brood care (Cotter \& Kilner 2010). These costs also

4 account for the additional fine-tuned plasticity in antibacterial production that we found in

5 response to a bacterial challenge to the carcass (Fig. 1). Presumably, by carefully modulating

6 production of antibacterial substances in their anal exudates in relation to the extent of

7 bacterial challenge, female beetles can minimize the fitness costs of mounting a social

8 immune response. The social immune system in the burying beetles thus appears to be

9 deployed in a relatively sophisticated way, and is seemingly just as plastic as the personal

10 immune response (see Wilson \& Cotter 2009 and references therein). What cues might

11 females use for adjusting investment in antibacterial activity in their anal exudates? In our

12 previous work, we found that lytic levels in the anal exudates decrease rapidly once beetles

13 are removed from the carcass suggesting that the presence of the carcass alone is sufficient to

14 trigger some antibacterial production (Cotter \& Kilner 2010). The experiments we describe

15 here suggest that the bacteria themselves present an additional cue, possibly detected orally as

16 has been shown in cabbage looper caterpillars (Freitak et al. 2007). However, we have not yet

17 determined whether beetles are responding to the presence of bacteria alone, or to specific

18 concentrations of bacteria on a carcass. It is worth noting that broth alone also appears to

19 upregulate antibacterial activity, though to a lesser extent than the bacterial treatments (Fig.

20 1). This may be because, whilst the broth is sterile, once it comes into contact with the

21 carcass it may encourage the replication of bacteria already present, thereby presenting a

22 heavier dose than the untreated carcasses, though still less than the bacteria-treated carcasses,

23 suggesting that there may indeed be dose response to bacterial contamination. 
1 The usage costs (sensu Schulenburg et al. 2009) of the social immune system that we report

2 here could arise simply through resource re-allocation (Sheldon \& Verhulst 1996).

3 Upregulating antibacterial activity in the anal exudates might cause females to divert

4 resources otherwise destined for tissue repair and/or egg production, thereby compromising

5 survival and reducing fecundity. It is likely that lytic activity is competing for specific

6 nutrients or amino acids rather than energy per se, due to the fact that survival does not differ

7 under starvation. Hormones could play a key role in mediating this resource allocation; a

8 single hormone can have antagonistic effects on tissues that are competing for resources

9 (Finch \& Rose 1995). Juvenile hormone (JH) is one such candidate hormone in the burying

10 beetle (Trumbo \& Robinson 2004). In a congeneric burying beetle to our study species, $N$.

11 orbicollis, $\mathrm{JH}$ levels are upregulated following the discovery of a carcass, and this $\mathrm{JH}$ surge

12 appears to initiate ovarian development and caring behaviour (Trumbo et al. 1995; Scott \&

13 Panaitof 2004). It is likely that this hormonal surge also initiates the upregulation of

14 antibacterial activity, along with the other parental care behaviours (Cotter \& Kilner 2010),

15 and the downregulation of PO, as has been shown in insect haemolymph (Rolff \& Siva-Jothy

16 2002; Rantala et al. 2003). Separate experiments have established that elevated JH levels also

17 reduce adult survival, at least when food is restricted, potentially via increasing the rate of

18 metabolism (Trumbo \& Robinson 2004). Thus, it is possible that increased JH levels may

19 result in the channelling of resources to reproduction, including the social immune response,

20 and away from somatic maintenance, although further experiments are necessary to test

21 whether this is the case or not.

22 Finally, defending a public resource brings fitness benefits to other individuals (Rozen

23 et al. 2008) but we have shown that this comes at some personal costs to females (Figure 3).

24 Therefore mounting a social immune response in the burying beetle is cooperative (Hamilton 
1 1964, West et al. 2007). In its narrowest sense, this form of cooperation (West et al. 2007) is

2 just like any other sort of parental investment, with females sacrificing their future fitness to

3 assist their offspring. Similarly, the female's investment in social immunity benefits her

4 partner too because presumably he then escapes some of the costs of defending the carcass

5 from bacteria. Exactly how these costs are divided between the breeding pair will be a source

6 of sexual conflict (Lessells 1999) and our experiments to date suggest that females are on the

7 losing side. Male anal exudates typically exhibit less antibacterial activity than those of their

8 partners (Cotter \& Kilner 2010), and males also have greater lifetime reproductive success,

9 when all else is equal between the sexes (Ward et al. 2009). Whether these two observations

10 are causally linked, and whether females can ever pass the costs of social immune defence

11 onto her partner (Chase 1980; Houston \& Davies 1985; McNamara et al. 1999) remain to be

12 determined in future work.

13 In nature, a carcass cannot always be monopolized by a single breeding pair and

14 uneasy breeding associations between three or more adults commonly arise (Müller et al.

15 2007). How should the costs of social immunity then be divided among the breeding adults

16 (who are unrelated)? If all adults arrive at the carcass at the same time, then the problem

17 resembles a public goods dilemma, in which each individual participates to achieve a

18 common good but at some cost to themselves (Dionisio \& Gordo 2006, Frank 2010).

19 Theoretical analyses suggest that where the common good is not diminishable (Dionisio \&

20 Gordo 2006), or where the group is dependent on the common good (Frank 2010), (as in this

21 case), then the evolutionary stable strategy is for everyone to make some contribution. But

22 adults do not always arrive at the carcass simultaneously (Eggert \& Müller 1997). Takeovers

23 of prepared carcasses are common (e.g. Trumbo 1990), presumably because the victorious

24 new owners thereby avoid some of the fitness costs associated with defending the carcass 
1 against bacterial rivals. Even in partial takeovers, when carcass owners cede some part of

2 their breeding resource to another adult (Trumbo 1990; Eggert \& Müller 1992), the incoming

3 breeder presumably benefits from the prior investment in social immune defence by the

4 resident beetles.

As well as potentially benefiting unrelated conspecifics, a female's investment in

6 social immunity can also potentially be of value to the wider carrion community, particularly

7 the phoretic nematodes (Richter 1993) and mites (Brown \& Wilson 1992; Schwarz \&

8 Koulianos 1998) who breed alongside the beetle's larvae on the carcass and who would

9 presumably gain from the beetle's antibacterial defences of the resource. Previous work on

10 other species of burying beetle has established that phoretic mites might themselves also

11 make a contribution to social immunity by foraging on any nematodes and microbes that take

12 up residence on the carcass (Wilson \& Knollenberg 1987; see also Biani et al. 2009). It

13 would be interesting to determine in future work whether the beetles and the phoretic

14 community make complementary contributions to social immunity, together providing a

15 more robust defence of the carcass than they would achieve alone, or whether the phoretic

16 community benefits the burying beetle directly by enabling it to reduce investment in social

17 immune defences.

In conclusion, our experiments show that mounting a social immune response has major fitness costs for females: females that upregulate their antibacterial activity produce only $84 \%$ of the offspring that control females manage to raise during their lives. The

21 challenge for future work is to identify the mechanisms responsible for these costs and to

22 determine how investment in social immunity is shared within burying beetle pairs, and breeding associations on a carcass, as well as among the wider carrion community. 


\section{Acknowledgments}

2 This work was supported by the The Leverhulme Trust (PLP/2006/0033 to RMK) and the

3 Department of Zoology, University of Cambridge, UK. We are very grateful to Per Smiseth

4 and Allen Moore for their logistical help and support in getting this project started. Author

5 contributions: SCC designed the experiments, collected and analysed the data, and co-wrote

6 the paper; ET and AJPP designed the experiments and collected the data; RMK co-wrote the 7 paper.

8

9 


\section{References}

2 Bartlett J. \& Ashworth C.M. (1988). Brood size and fitness in Nicrophorus vespilloides

3

4 Biani N., Mueller U. \& Wcislo W. (2009). Cleaner mites: Sanitary mutualism in the 5

6 Bonneaud C., Mazuc J., Gonzalez G., Haussy C., Chastel O., Faivre B. \& Sorci G. (2003). 7 (Coleoptera, Silphidae). Behav. Ecol. Sociobiol., 22, 429-434. Assessing the cost of mounting an immune response. Am. Nat., 161, 367-379.

Brown J.M. \& Wilson D.S. (1992). Local specialization of phoretic mites on sympatric carrion beetle hosts. Ecology, 73, 463-478.

Cardoza Y.J., Klepzig K.D. \& Raffa K.F. (2006). Bacteria in oral secretions of an endophytic insect inhibit antagonistic fungi. Ecol. Entomol., 31, 636-645.

Chase I.D. (1980). Cooperative and non-cooperative behavior in animals. Am. Nat., 115, 827857.

Cotter, S.C, Myatt, J., Benskin, C. \& Wilson, K. (2008a) Selection for cuticular melanism reveals immune function and life-history trade-offs in Spodoptera littoralis. J. Evol. Biol, 21, 1744-1754.

Cotter, S.C., Beveridge, M. \& Simmons, L.W. (2008b) Male morph predicts investment in larval immune function in the dung beetle, Onthophagus taurus. Behav. Ecol., 19, $331-337$

Cotter S.C. \& Kilner R. (2010a) Personal immunity versus social immunity. Behav. Ecol.,In Press 
1 Cotter S.C. \& Kilner R. (2010b). Sexual division of antibacterial resource defence in breeding burying beetles, Nicrophorus vespilloides. J. Anim. Ecol., 79, 35-43

3 Cremer S., Armitage S.A.O. \& Schmid-Hempel P. (2007). Social immunity. Curr. Biol., 17, 4 R693-R702.

5 Dionisio F. \& Gordo I. (2006) The tragedy of the commons, the public goods dilemma, and the meaning of rivalry and excludability in evolutionary biology. Evol. Ecol. Res., 8, 321-332.

Eggert A.K. \& Müller J.K. (1992). Joint breeding in female burying beetles. Behav. Ecol. Sociobiol., 31, 237-242.

Eggert A.K. \& Müller J.K. (1997). Biparental care and social evolution in burying beetles: lessons from the larder. In: The Evolution of Social Behavior in Insects and Arachnids (Eds. Choe J.C. \& Crespi B.J.). Cambridge: Cambridge University Press. p. 216-236.

Fernandez-Marin H., Zimmerman J.K., Nash D.R., Boomsma J.J. \& Wcislo W.T. (2009). Reduced biological control and enhanced chemical pest management in the evolution of fungus farming in ants. Proc. R. Soc. B, 276, 2263-2269.

Finch C.E. \& Rose M.R. (1995). Hormones and the Physiological Architecture of LifeHistory Evolution. Q. Rev. Biol., 70, 1-52.

Frank, S. A. (2010). A general model of the public goods dilemma. J. Evol. Biol. Doi:10.1111/j.1420-9101.2010.01986.x

Freitak D., Wheat C.W., Heckel D.G. \& Vogel H. (2007). Immune system responses and fitness costs associated with consumption of bacteria in larvae of Trichoplusia ni. BMC Biol., 5, 56. 
1 Giacomello E., Marchini D. \& Rasotto M.B. (2006). A male sexually dimorphic trait provides antimicrobials to eggs in blenny fish. Biol. Lett., 2, 330-333.

3 Hamilton W.D. (1964). The genetical evolution of social behaviour I. J. Theor. Biol., 7,1-16.

4 Houston A.I. \& Davies N.B. (1985). The evolution of cooperation and life history in the dunnock Prunella modularis. In: Behavioural Ecology: Ecological Consequences of Adaptive Behaviour (eds R. M. Sibly \& R. H. Smith), Blackwell Science, Oxford, pp 471-487.

Ilmonen P., Taarna T. \& Hasselquist D. (2000). Experimentally activated immune defence in female pied flycatchers results in reduced breeding success. Proc. $R$. Soc. B, 267, 665670.

Jacot A., Scheuber H. \& Brinkhof M.W.G. (2004). Costs of an induced immune response on sexual display and longevity in field crickets. Evolution, 58, 2280-2286.

Knouft J.H., Page L.M. \& Plewa M.J. (2003). Antimicrobial egg cleaning by the fringed darter (Perciformes : Percidae : Etheostoma crossopterum): implications of a novel component of parental care in fishes. Proc. R. Soc. B, 270, 2405-2411.

Lessells C.M. (1999). Sexual conflict in animals. In: Levels of Selection in Evolution (ed Keller, L.). Princeton University Press, Princeton, pp. 75-99.

Little T.J., Perutz M., Palmer M., Crossan C. \& Braithwaite V.A. (2008). Male three-spined sticklebacks Gasterosteus aculeatus make antibiotic nests: a novel form of parental protection? J. Fish Biol., 73, 2380-2389.

Lochmiller R.L. \& Deerenberg C. (2000). Trade-offs in evolutionary immunology: just what is the cost of immunity? Oikos, 88, 87-98. 
1 McNamara J.M., Gasson C.E. \& Houston A.I. (1999). Incorporating rules for responding into evolutionary games. Nature, 401, 368-371.

3 Moret Y. \& Schmid-Hempel P. (2000). Survival for immunity: The price of immune system activation for bumblebee workers. Science, 290, 1166-1168.

Müller J.K., Braunisch V., Hwang W.B. \& Eggert A.K. (2007). Alternative tactics and individual reproductive success in natural associations of the burying beetle, Nicrophorus vespilloides. Behav. Ecol., 18, 196-203.

Nascimento R.R.D., Schoeters E., Morgan E.D., Billen J. \& Stradling D.J. (1996). Chemistry of metapleural gland secretions of three attine ants, Atta sexdens rubropilosa, Atta cephalotes, and Acromyrmex octospinosus (Hymenoptera: Formicidae). J. Chem. Ecol., 22, 987-1000.

Povey, S.R., Cotter, S.C., Simpson, S.J., Lee, K. \& Wilson, K. (2009) Can the protein costs of bacterial resistance be offset by altered feeding behaviour? J. A. Ecol., 78, 437-446.

Prendeville H.R. \& Stevens L. (2002). Microbe inhibition by Tribolium flour beetles varies with beetle species, strain, sex, and microbe group. J. Chem. Ecol., 28, 1183-1190.

Pukowski E. (1933). Okoloische untersuchungen an Necrophorus. Zeitschrift fur Morphologie und Oekologie der Tiere, 27, 518-586.

Rantala, M.J. \& Kortet, R. (2003) Courtship song and immune function in the field cricket Gryllus bimaculatus. Biol. J. Linn. Soc., 79, 503-510.

Rantala M.J., Vainikka A. \& Kortet R. (2003) The role of juvenile hormone in immune function and pheromone production trade-offs: a test of the immunocompetence handicap principle. Proc. $R$. Soc. B, 270, 2257-2261 
1 Richter S. (1993). Phoretic association between the dauerjuveniles of Rhabditis stammeri (Rhabditidae) and life-history stages of the burying beetle Nicrophorus vespilloides (Coleoptera, Silphidae). Nematologica, 39, 346-355.

Rolff J. \& Siva-Jothy M.T. (2002) Copulation corrupts immunity: A mechanism for a cost of 5 mating in insects. Proc. Natl. Acad. Sci. USA, 99, 9916-9918

Rosengaus R.B., Guldin M.R. \& Traniello J.F.A. (1998). Inhibitory effect of termite fecal 7 pellets on fungal spore germination. J. Chem. Ecol., 24, 1697-1706.

Rozen D.E., Engelmoer D.J.P. \& Smiseth P.T. (2008). Antimicrobial strategies in burying beetles breeding on carrion. Proc. Natl. Acad Sci. USA, 105, 17890-17895.

Schulenburg H., Kurtz J., Moret Y. \& Siva-Jothy M.T. (2009). Introduction. Ecological immunology. Philos. Trans. R. Soc. B., 364, 3-14.

Schwarz H.H. \& Koulianos S. (1998). When to leave the brood chamber? Routes of dispersal in mites associated with burying beetles. Exp. Appl. Acarol., 22, 621-631.

Scott M.P. (1998). The ecology and behavior of burying beetles. Ann Rev Entomol., 43, 595618.

Scott M.P. \& Panaitof S.C. (2004). Social stimuli affect juvenile hormone during breeding in biparental burying beetles (Silphidae: Nicrophorus). Horm. Behav., 45, 159-167.

Sheldon B.C. \& Verhulst S. (1996). Ecological immunology: costly parasite defences and

Siva-Jothy M.T. \& Thompson J.J.W. (2002). Short-term nutrient deprivation affects immune function. Physiol. Entomol., 27, 206-212. 
1 Trumbo S.T. (1990). Interference competition among burying beetles (Silphidae, Nicrophorus). Ecol. Entomol., 15, 347-355.

3 Trumbo S.T., Borst D.W. \& Robinson G.E. (1995). Rapid elevation of juvenile hormone titer during behavioral assessment of the breeding resource by the burying beetle, Nicrophorus orbicollis. J. Insect Physiol., 41, 535-543.

Trumbo S.T. \& Robinson G.E. (2004). Nutrition, hormones and life history in burying beetles. J. Insect Physiol., 50, 383-391.

Ward R.J.S., Cotter S.C. \& Kilner R.M. (2009). Current brood size and residual reproductive value predict offspring desertion in the burying beetle Nicrophorus vespilloides. Behav. Ecol. doi:10.1093/beheco/arp132

West S. A., Griffin A. S. \& Gardner A. (2007) Social semantics: altruism, cooperation, mutualism, strong reciprocity and group selection. J. Evol. Biol. 20, 415-432.

Wilson D. \& Knollenberg W. (1987). Adaptive indirect effects: the fitness of burying beetles with and without their phoretic mites. Evol. Ecol., 1, 139-159.

Wilson K. \& Cotter S.C. (2009). Density-dependent prophylaxis in insects. In: Insects and Phenotypic Plasticity: Mechanisms and Consequences. (eds. Ananthakrishnan TN \& Whitman DW). Science Publishers, Inc. Plymouth, UK., pp. 137-176. 


\section{$1 \quad$ Figure legends}

\section{Figure 1}

3 Experiment 1: Mean $( \pm$ SE) lytic activity measured in exudates collected from females that

4 had been presented with a carcass that had either been untreated (control), dipped in sterile

5 nutrient broth (broth) or dipped in a solution of heat-killed (dead bacteria) or live $M$.

$6 \quad$ lysodeikticus cells in nutrient broth (live bacteria).

\section{Figure 2}

9 Experiment 3: Cumulative percentage survival for females that had bred twice on a carcass

10 that had either been dipped in nutrient broth (sterile broth) or dipped in a solution of heat-

11 killed (dead bacteria) or live M. lysodeikticus cells in nutrient broth (live bacteria). Females

12 were then repeatedly bred on untreated carcasses until death.

\section{$14 \quad$ Figure 3}

15 Experiment 3: a) number of offspring, b) average offspring mass and c) total offspring mass

16 per brood produced by females that had been bred continuously thoughout their lives.

17 Females were bred twice on a carcass that had either been dipped in nutrient broth (broth) or

18 dipped in a solution of heat-killed (dead bacteria) or live M. lysodeikticus cells in nutrient

19 broth (live bacteria), subsequent carcasses were untreated. All values displayed are estimates

20 from the minimum adequate model controlling for the weight of the mouse carcass that

21 females were provided with and for the random family and individual ID effects. 


\section{Tables}

\section{Table 1}

3 Experiment 3: Estimates of goodness of fit of the models of lifetime reproductive success for

4 beetles that had been bred twice on a carcass that had either dipped in nutrient broth or

5 dipped in a solution of dead or live M. lysodeikticus cells in nutrient broth, subsequent

6 carcasses were untreated. The minimum adequate model in each case and its corresponding

$7 \quad \mathrm{r}^{2}$ value are highlighted in bold.

8

\begin{tabular}{lll}
\hline Response & Terms included & $\mathbf{r}^{2}$ \\
\hline number of offspring & carcass weight + brood*treatment & $\mathbf{0 . 3 8}$ \\
& carcass weight + brood + treatment & 0.37 \\
& carcass weight + brood & 0.36 \\
mean larval mass & carcass weight + brood*treatment & $\mathbf{0 . 3 9}$ \\
& carcass weight + brood + treatment & 0.37 \\
carcass weight + brood & 0.35 \\
carcass weight + brood*treatment & $\mathbf{0 . 5 3}$ \\
& carcass weight + brood + treatment & 0.51 \\
& carcass weight + brood & 0.50 \\
\hline
\end{tabular}

9 


\section{Figures}

\section{Figure 1}

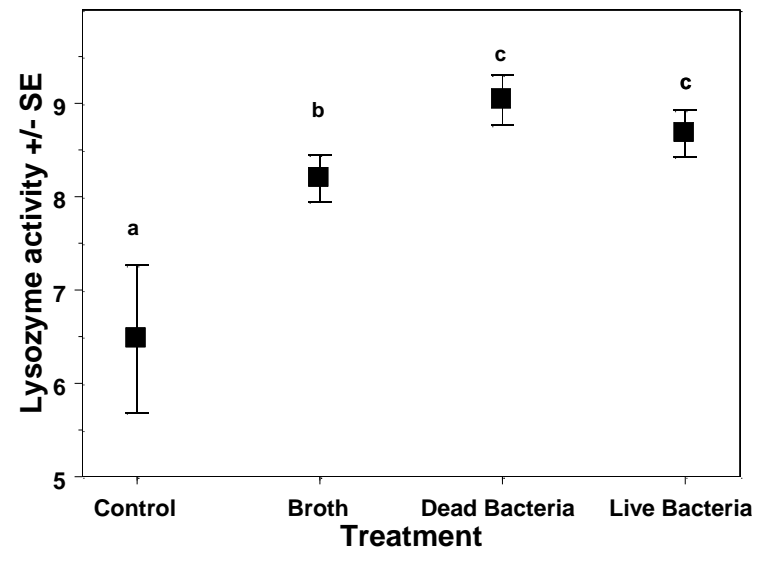

3 
$1 \quad$ Figure 2

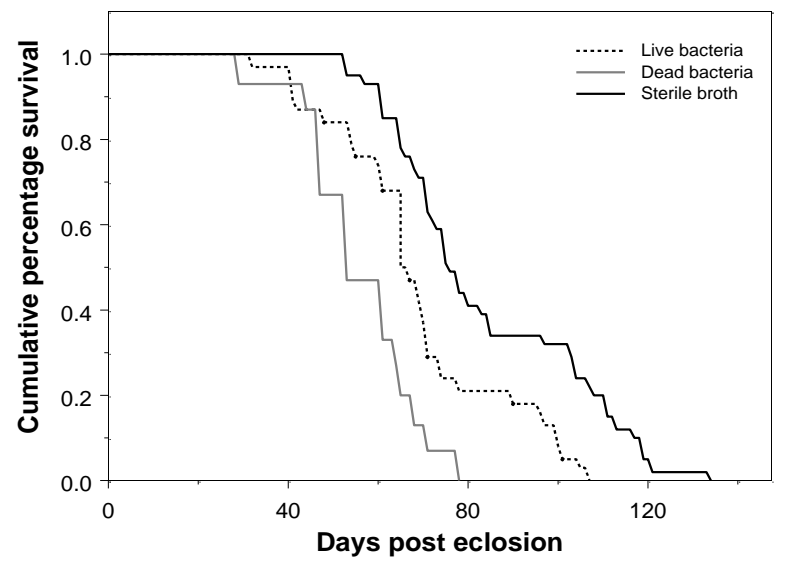

3 


\section{$1 \quad$ Figure 3}

a)

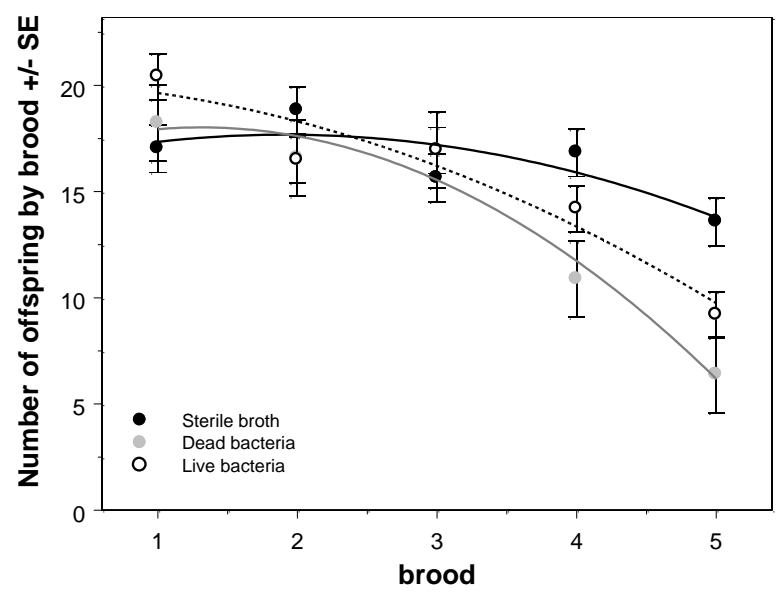

b)

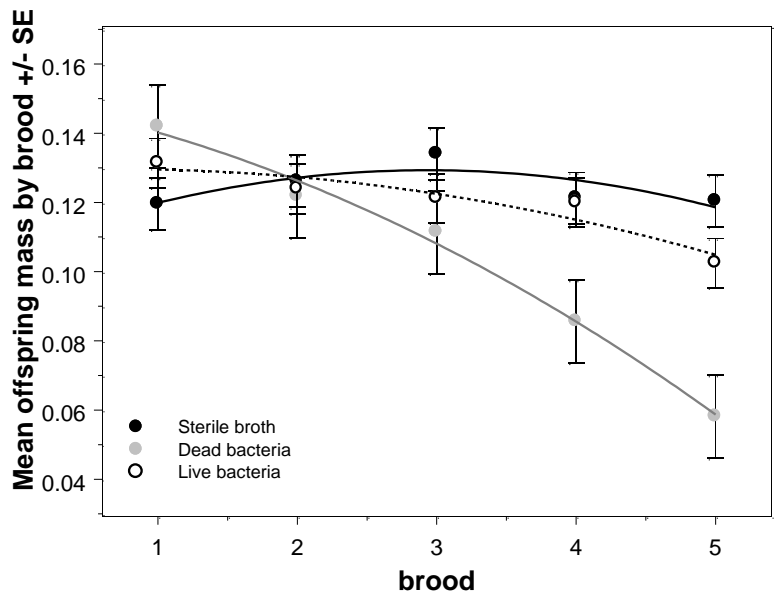

c)

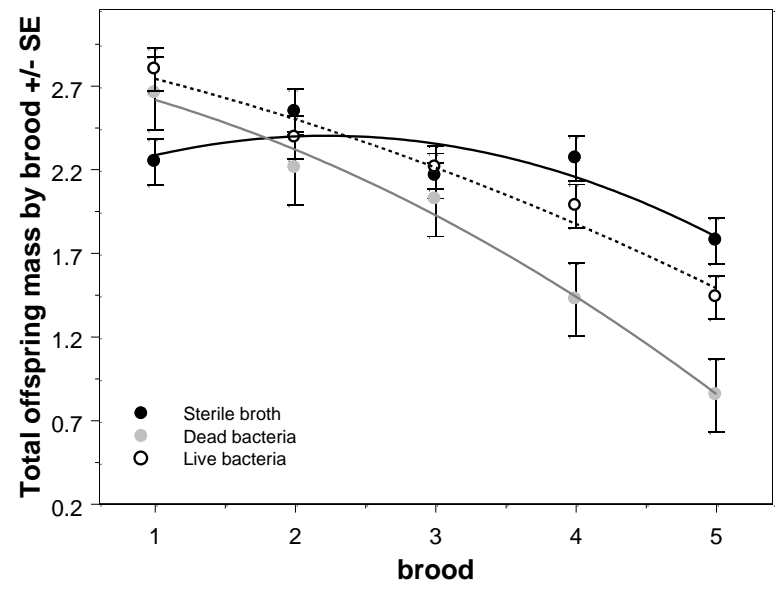

